\title{
Whey protein concentrate enhances intestinal integrity and influences transforming growth factor- $\beta 1$ and mitogen-activated protein kinase signalling pathways in piglets after lipopolysaccharide challenge
}

\author{
Kan Xiao, Lefei Jiao, Shuting Cao, Zehe Song, Caihong Hu* and Xinyan Han* \\ The Key Laboratory of Molecular Animal Nutrition, Ministry of Education, Animal Science College, Zhejiang University, \\ Hangzhou 310058, China
}

(Submitted 27 May 2015 - Final revision received 15 November 2015 - Accepted 17 November 2015 - First published online 26 January 2016)

\section{Abstract}

Whey protein concentrate (WPC) has been reported to have protective effects on the intestinal barrier. However, the molecular mechanisms involved are not fully elucidated. Transforming growth factor- $\beta 1$ (TGF- $\beta 1$ ) is an important component in the WPC, but whether TGF- $\beta 1$ plays a role in these processes is not clear. The aim of this study was to investigate the protective effects of WPC on the intestinal epithelial barrier as well as whether TGF- $\beta 1$ is involved in these protection processes in a piglet model after lipopolysaccharide (LPS) challenge. In total, eighteen weanling pigs were randomly allocated to one of the following three treatment groups: (1) non-challenged control and control diet; (2) LPS-challenged control and control diet; (3) LPS + 5\%WPC diet. After $19 \mathrm{~d}$ of feeding with control or $5 \%$ WPC diets, pigs were injected with LPS or saline. At $4 \mathrm{~h}$ after injection, pigs were killed to harvest jejunal samples. The results showed that WPC improved $(P<0 \cdot 05)$ intestinal morphology, as indicated by greater villus height and villus height:crypt depth ratio, and intestinal barrier function, which was reflected by increased transepithelial electrical resistance and decreased mucosal-to-serosal paracellular flux of dextran ( $4 \mathrm{kDa})$, compared with the LPS group. Moreover, WPC prevented the LPS-induced decrease $(P<0.05)$ in claudin-1, occludin and zonula occludens-1 expressions in the jejunal mucosae. WPC also attenuated intestinal inflammation, indicated by decreased $(P<0.05)$ mRNA expressions of TNF- $\alpha$, IL-6, IL- 8 and IL-1 $\beta$. Supplementation with WPC also increased $(P<0.05)$ TGF- $\beta 1$ protein, phosphorylated-Smad 2 expression and Smad 4 and Smad7 mRNA expressions and decreased $(P<0.05)$ the ratios of the phosphorylated to total c-jun N-terminal kinase (JNK) and p38 (phospho-JNK:JNK and p-p38:p38), whereas it increased $(P<0.05)$ the ratio of extracellular signal-regulated kinase (ERK) (phospho-ERK:ERK). Collectively, these results suggest that dietary inclusion of WPC attenuates the LPS-induced intestinal injury by improving mucosal barrier function, alleviating intestinal inflammation and influencing TGF- $\beta 1$ canonical Smad and mitogen-activated protein kinase signalling pathways.

Key words: Whey protein concentrate: Intestinal integrity: Transforming growth factor- $\beta 1$ : Mitogen-activated protein kinase: Piglets

Whey protein concentrate (WPC) is a protein-enriched powder made from whey during the process of cheese making. It is commonly used in the manufacturing of foods for infants and young children. Emerging evidence has demonstrated that WPC is useful for the treatment of a wide variety of gastrointestinal disorders such as inflammatory bowel disease and necrotising enterocolitis $^{(1,2)}$. It has been found that the beneficial role of WPC in the intestine is closely related to its numerous bioactive compounds including functional amino acids, lactoferrin (LF) and growth factors, which is largely attributed to the stimulation of mucin synthesis and modification of immune response ${ }^{(2,3)}$. Recently, it has also been reported that WPC improves intestinal epithelial barrier function in vitro ${ }^{(4)}$. However, the molecular mechanisms underlying the protective effects are poorly understood.
WPC contains abundant bioactive compounds that are vital for immune and gut development early in life ${ }^{(5,6)}$. Among the most relevant substances in WPC are Ig, LF and growth factors (e.g. transforming growth factor $\beta$ (TGF- $\beta$ ) and epidermal growth factor (EGF)). Nevertheless, investigations directly examining the role of WPC in affecting the barrier integrity in vivo have not been reported. It is also of great interest to investigate whether bioactive compounds in WPC can be partly involved in WPC-induced prevention of intestinal epithelial barrier disruption. Until now, there are little data about the role of WPC in restitution of intestinal epithelium after injury ${ }^{(4)}$.

Mammalian milk and WPC are rich in TGF- $\beta$ including TGF- $\beta 1^{(4,7)}$. TGF- $\beta 1$ is also the most abundant isoform in the mucosa of the gut ${ }^{(8)}$ and may play an important role in postnatal adaptation of the gastrointestinal tract in suckling animals ${ }^{(9)}$.

Abbreviations: EGF, epidermal growth factor; ERK, extracellular signal-regulated kinase; FD4, fluorescein isothiocyanate dextran 4 kDa; JNK, c-jun N-terminal kinase; LF, lactoferrin; LPS, lipopolysaccharide; MAPK, mitogen-activated protein kinase; TER, transepithelial electrical resistance; TGF- $\beta 1$, transforming growth factor- $\beta 1$; WPC, whey protein concentrate; ZO-1, zonula occludens-1.

*Corresponding authors: Dr C. Hu, email chhu@zju.edu.cn; Dr X. Han, email xyhan@zju.edu.cn 
TGF- $\beta 1$ is of particular interest as it has known effects in remarkable number of biological processes, including epithelial cell growth and differentiation ${ }^{(10,11)}$, restitution of intestinal epithelium after injury ${ }^{(9,12)}$ and immune regulation ${ }^{(5)}$. Thus far, different signalling pathways have been reported to be involved in TGF- $\beta$ action, including Smad-dependent and Smad-independent pathways ${ }^{(13)}$. The canonical TGF- $\beta$ signalling pathway is mediated by Smad family proteins ${ }^{(13)}$. Besides the canonical Smad pathways, there have been a number of non-Smad signalling pathways described, including mitogenactivated protein kinase (MAPK pathways) (extracellular signalregulated kinase (ERK), c-jun N-terminal kinase (JNK) and p38 MAPK pathways) in TGF- $\beta 1$ actions $^{(14)}$. We hypothesised that TGF- $\beta 1$ in WPC might be involved in those barrierprotection processes and would lead to changes of these TGF- $\beta$ signalling pathways. In the present study, we used a piglet model challenged with lipopolysaccharide (LPS) to investigate the beneficial effects of WPC on intestinal epithelial barrier function. Moreover, intracellular signals through which WPC and its active components might exert beneficial barrier effects were studied.

\section{Methods}

\section{Animal care and experimental design}

This experiment was approved by the Animal Care and Use Committee, Zhejiang University. A total of eighteen 35-d-old weaned barrows (Duroc $\times$ Landrace $\times$ Yorkshire, weaned at $21 \mathrm{~d}$ of age), with an average weight of $9.5 \mathrm{~kg}$, were allocated to three groups, each consisting of six animals. One group served as the control group, whereas the other two groups were subjected to intestinal injury by injecting LPS. Animals were fed diets according to their groups: (1) control group (piglets fed the control diet); (2) LPS group (piglets fed the control diet and LPS); (3) LPS + WPC group (piglets fed the diet inclusion of $5 \%$ WPC; WPC was provided by Open Country Dairy Ltd). Pigs were individually housed in pens with dimensions of $1.8 \times 1.1 \mathrm{~m}^{2}$ in an environmentally controlled nursery barn. The room temperature was maintained at $25-27^{\circ} \mathrm{C}$. Each pen contained a feeder and a nipple waterer to allow piglets ad libitum access to feed and water. There were six replicate pens for each treatment. Diets were formulated to meet or exceed requirements as suggested by the National Research Council (2012) (Table 1). The crude protein, $\mathrm{Ca}$ and total $\mathrm{P}$ contents in diet were analysed according to the method of Association of Official Analytical Chemists $^{(15)}$. After $19 \mathrm{~d}$ feeding with control or $5 \%$ WPC diets, the two challenged groups (the LPS group and the LPS + WPC group) were intraperitoneally injected with Escherichia coli LPS (E. coli serotype 055: B5; Sigma Chemical) at $100 \mu \mathrm{g} / \mathrm{kg}$ body weight (BW), and the unchallenged group was injected with the same amount of $0.9 \% \mathrm{NaCl}$ solution. The dose of LPS was chosen to cause acute intestinal injury in weaned pigs according to Liu et $a .^{(16-18)}$

\section{Sample collection}

Four hours following the injection of LPS or saline, piglets were killed under anaesthesia with an intravenous injection of
Table 1. Ingredients and chemical composition of the weaned diets on an as-fed basis

\begin{tabular}{lcc}
\hline Items & Control diet & $5 \%$ WPC \\
\hline Ingredients (g/kg) & & \\
Maize & 633.5 & 611.9 \\
Soyabean meal & 265 & 236 \\
Fishmeal & 55 & $53 \cdot 3$ \\
WPC (crude protein 350 g/kg) & & 50 \\
Limestone meal & 5 & 5 \\
Dicalcium phosphate & 11.5 & 12 \\
Sodium chloride & 3 & 3 \\
L-Lysine HCl & 1.5 & 1.3 \\
DL-Methionine & 0.5 & 0.5 \\
Vitamin-mineral premix* & 10 & 10 \\
Soyabean oil & 15 & 17 \\
Composition (g/kg) & & 14.32 \\
Digestible energy† (calculated) $(\mathrm{MJ} / \mathrm{kg})$ & 14.33 & 219.5 \\
Crude protein (measured) & 219.6 & 13.9 \\
Lysine (measured) & 13.7 & 4.5 \\
Methionine (measured) & 4.4 & 8.3 \\
Ca (measured) & 8.2 & 6.6 \\
Total P (measured) & 6.8 & 3 \\
TGF- $\beta 1$ (measured) ( $\mu \mathrm{gg} / \mathrm{kg}$ ) & & \\
\hline
\end{tabular}

WPC, whey protein concentrate; TGF- $\beta 1$, transforming growth factor- $\beta 1$.

* Provided per kilogram of diet: vitamin A, $3.3 \mathrm{mg}$; vitamin $E, 33.4 \mathrm{mg}$; vitamin $D_{3}$, $0.015 \mathrm{mg}$; vitamin $\mathrm{K}_{3}, 1.5 \mathrm{mg}$; biotin, $0.10 \mathrm{mg}$; riboflavin, $8.0 \mathrm{mg}$; thiamine, $2.0 \mathrm{mg}$; niacin, $30 \mathrm{mg}$; pantothenic acid, $20 \mathrm{mg}$; pyridoxine, $3.0 \mathrm{mg}$; folic acid, $0.6 \mathrm{mg}$; vitamin $\mathrm{B}_{12}, 0.04 \mathrm{mg}$; choline, $800 \mathrm{mg}$; $\mathrm{Cu}\left(\mathrm{CuSO}_{4} \cdot 5 \mathrm{H}_{2} \mathrm{O}\right), 16 \mathrm{mg}$; $\mathrm{Fe}\left(\mathrm{FeSO}_{4}\right)$, $125 \mathrm{mg} ; \mathrm{Zn}\left(\mathrm{ZnSO}_{4}\right), 100 \mathrm{mg} ; \mathrm{Mn}\left(\mathrm{MnSO}_{4} \cdot \mathrm{H}_{2} \mathrm{O}\right), 15 \mathrm{mg}$; Se $\left(\mathrm{Na}_{2} \mathrm{SeO}_{3}\right), 0.3 \mathrm{mg}$; $\mathrm{I}(\mathrm{KI}), 0.2 \mathrm{mg}$

† Digestible energy was calculated from data provided by Feed Database in China (2011).

sodium pentobarbital ( $40 \mathrm{mg} / \mathrm{kg} \mathrm{BW})$. The reason for the choice of measurement at one point $(4 \mathrm{~h})$ after LPS injection was because previous studies have demonstrated that, within 3-6 h after injection, LPS caused acute intestinal morphological damage and a breakdown in intestinal barrier function in rats, mice and pigs ${ }^{(16-22)}$. Jejunum is one of the most susceptible intestinal segment to damage from endotoxins (LPS) ${ }^{(23)}$. Segments of the mid-jejunum were harvested immediately after the animals were killed and prepared for Ussing chamber studies. Adjacent specimens were fixed in buffered $10 \%$ formalin until morphological measurements. Mucosal scrapings from the remaining jejunum samples were collected, rapidly frozen in liquid $\mathrm{N}_{2}$ and stored at $-80^{\circ} \mathrm{C}$.

\section{Intestinal morphology and barrier function}

After fixation, the intestinal segments were dehydrated, embedded in paraffin, sectioned $(5 \mu \mathrm{m})$ and stained with haematoxylin and eosin ${ }^{(24)}$. Villus height and crypt depth were measured in three intestinal cross-sections per animal with at least ten well-oriented crypt-villus units for each cross-section using image analysis (Leica Imaging Systems Limited) and averaged for each sample. The transepithelial electrical resistance (TER) and mucosal-to-serosal permeability to 4-kDa FITC dextran (fluorescein isothiocyanate dextran $4 \mathrm{kDa}$ (FD4); Sigma-Aldrich) were determined in vitro in a Ussing chamber system, according to the procedures outlined by Moeser et $a l .{ }^{(25)}$. In brief, segments of the jejunum were stripped from the seromuscular layer in oxygenated $\left(95 \% \mathrm{O}_{2} / 5 \% \mathrm{CO}_{2}\right)$ Ringer's solution and then mounted in the Easy Mount Ussing 
chamber system with a multi-channel voltage-current clamp (model VCC MC6; Physiologic Instruments). Tissues were bathed on the serosal and mucosal sides with $5 \mathrm{ml}$ Ringer's solution. The serosal bathing solution contained $10 \mathrm{~mm}$ glucose, which was osmotically balanced on the mucosal side with $10 \mathrm{~mm}$ mannitol. Bathing solutions were oxygenated $\left(95 \% \mathrm{O}_{2}-5 \% \mathrm{CO}_{2}\right)$ and circulated in water-jacketed reservoirs maintained at $37^{\circ} \mathrm{C}$. The clamps were connected to Acquire and Analyze software (Physiologic Instruments) for automatic data collection. After a 30-min equilibration period on the Ussing chambers, TER $\left(\Omega \mathrm{cm}^{2}\right)$ was recorded at 15 -min intervals over a 2 - $h$ period and then averaged to derive the TER values for a given pig. FD4 was added on the mucosal side at a final concentration of $0.375 \mathrm{mg} / \mathrm{ml}$. Mucosal-to-serosal flux of FD4 $\left(\mu \mathrm{g} / \mathrm{cm}^{2}\right.$ per $\left.\mathrm{h}\right)$ was monitored from the serosal side at $30-\mathrm{min}$ intervals for $120 \mathrm{~min}$. The concentrations of FD 4 in the serosal side were measured using a fluorescence microplate reader (FLx800; Bio-Tek Instruments Inc.). The flux over the 2-h period was calculated.

\section{Transforming growth factor- $\beta 1$ content in whey protein concentrate by ELISA measurements}

The TGF- $\beta 1$ content in WPC was determined by ELISA according to the manufacturer's protocol (R\&D Systems) ${ }^{(37)}$. TGF- $\beta 1$ content was also assayed in the control group.

\section{Protein expression analysis by Western blot}

The Western blot analysis was performed according to the procedures outlined by Hu et al. ${ }^{(24)}$. In brief, after electrophoresis, the proteins were transferred to polyvinylidene difluoride membranes (Millipore). The membranes were incubated overnight at $4^{\circ} \mathrm{C}$ with primary Antibody (Ab) and then with the secondary
$\mathrm{Ab}$ for $120 \mathrm{~min}$ at room temperature. The primary $\mathrm{Ab}$ (occludin, claudin-1, zonula occludens-1 (ZO-1), TGF- $\beta 1$, Smad2, phospho-Smad2, p38, phospho-p38, JNK, phospho-JNK (p-JNK), ERK, phospho-ERK 1/2 (p-ERK), $\beta$-actin rabbit mAb) were purchased from Santa Cruz Technology Inc. The secondary $\mathrm{Ab}$ was HRP-conjugated anti-rabbit antibody (Cell Signaling Technology). Western blot was detected using an enhanced chemiluminescence detection kit (Amersham), photographed by a ChemiScope 3400 (Clinx Science Instruments) and analysed using Quantity One software. $\beta$-Actin was used as an internal control, which exhibited no difference among each group. The relative abundance of each target protein was expressed as target protein: $\beta$-actin protein ratio or ratio of phosphorylated protein:total protein. The protein expression of all samples was expressed as fold changes, calculated relative to the control group.

\section{mRNA expression analysis by real-time PCR}

The mRNA levels of TNF- $\alpha$, IL- $1 \beta$, IL- 6 , IL- 8 and TGF- $\beta$ receptors, as well as their downstream signal Smads $(2,3,4,7)$, were determined by real-time PCR, as described by Liu et al. ${ }^{(17)}$. In brief, total RNA was extracted from jejunal mucosa using TRIzol reagent (Invitrogen) following the manufacturer's guidelines. The purity and concentration of all RNA samples were measured using a NanoDrop spectrophotometer (ND-2000; NanoDrop Technologies). Reverse transcription using the PrimeScript RT reagent kit (Takara Biotechnology) was carried out following the manufacturer's instructions. Quantitative analysis of PCR was carried out on a StepOne Plus real-time PCR system (Applied Biosystems) using SYBR Green Master mix (Promega) according to the manufacturer's instructions. The primers used are given in Table 2. Gene-specific amplification was determined by melting curve analysis and agarose gel electrophoresis. The $2^{-\Delta \Delta C_{t}}$ method

Table 2. GenBank accession numbers, sequences of forward and reverse primers and fragment sizes used for real-time PCR

\begin{tabular}{|c|c|c|c|}
\hline Target & GenBank number & Primer sequence & Size (bp) \\
\hline TNF- $a$ & NM_214022.1 & $\begin{array}{l}\text { F:5'CATCGCCGTCTCCTACCA3' } \\
\text { R:5'CCCAGATTCAGCAAAGTCCA3' }\end{array}$ & 199 \\
\hline IL-6 & NM_001252429.1 & $\begin{array}{l}\text { F:5'CCTGTCCACTGGGCACATAAC3' } \\
\text { R:5'CAAGAAACACCTGGCTCTGAAAC3' }\end{array}$ & 253 \\
\hline IL-8 & M86923 & $\begin{array}{l}\text { F:5'TGGCAGTTTTCCTGCTTTCT 3' } \\
\text { R:5'CAGTGGGGTCCACTCTCAAT 3' }\end{array}$ & 154 \\
\hline $\mathrm{IL}-1 \beta$ & NM_214055 & $\begin{array}{l}\text { F:5'CAAAGGCCGCCAAGATATAA 3' } \\
\text { R:5'GAAATTCAGGCAGCAACAT 3' }\end{array}$ & 147 \\
\hline $\mathrm{T} \beta \mathrm{RI}$ & AF461808 & $\begin{array}{l}\text { F:5'CTGTGTCTGTCCACCATTCATTTGG3' } \\
\text { R:5'CAACTTTGCTATGTCTGTCTCCCC3' }\end{array}$ & 496 \\
\hline $\mathrm{T} \beta \mathrm{R} I \mathrm{I}$ & X70142 & $\begin{array}{l}\text { F:5'CATCTCCTGCTAATGTTGTTGCC3' } \\
\text { R:5'CGGTTCTAAATCCTGGGACACG3' }\end{array}$ & 324 \\
\hline Smad2 & BP437096 & $\begin{array}{l}\text { F:5'GAAGAGAAGTGGTGTGAGAAAGCAG3' } \\
\text { R:5'AATACTGGAGGCAAAACTGGTGTC3' }\end{array}$ & 428 \\
\hline Smad3 & AB052738 & $\begin{array}{l}\text { F:5'TGGAGGAGGTGGAGAAATCAGAAC3' } \\
\text { R:5'CACACTCGCTTGCTCACTGTAATC3' }\end{array}$ & 541 \\
\hline Smad4 & NM 214072 & $\begin{array}{l}\text { F:5'CCTGAGTATTGGTGTTCCATTGC3' } \\
\text { R:5'TGATGCTCTGCCTTGGGTAATC3' }\end{array}$ & 598 \\
\hline Smad7 & AW359979 & $\begin{array}{l}\text { F:5'TACTGGGAGGAGAAGACGAGAGTG3' } \\
\text { R:5'TGGCTGACTTGATGAAGATGGG3' }\end{array}$ & 241 \\
\hline GAPDH & NM001206359 & $\begin{array}{l}\text { F:5'ATGGTGAAGGTCGGAGTGAAC3' } \\
\text { R:5'CTCGCTCCTGGAAGATGGT3' }\end{array}$ & 235 \\
\hline
\end{tabular}

$\mathrm{T} \beta \mathrm{RI}$, transforming growth factor- $\beta$ receptor I; T $\beta \mathrm{RII}$, transforming growth factor- $\beta$ receptor II; GAPDH, glyceraldehyde 3-phosphate dehydrogenase. 
was used to analyse the relative changes in each target gene expression. The change $(\Delta)$ in $C_{t}$ values in each group was compared with the $C_{t}$ value of glyceraldehyde 3-phosphate dehydrogenase (GAPHH) $\left(\Delta C_{t}\right)$. Subsequently, $\Delta \Delta C_{t}$ was computed for each target gene from the treatment groups by subtracting the averaged $\Delta C_{t}$ for the control group. The final fold differences were computed as $2^{-\Delta \Delta C_{t}}$ for each target gene. The results showed that GAPDH exhibited no difference between the three groups.

\section{Statistical analysis}

Data were analysed using the SAS statistical package (SAS Institute), with each animal considered an experimental unit. Results were statistically analysed by one-way ANOVA. Differences between the means were tested using Duncan's multiple range tests. Differences were considered significant at $P<0 \cdot 05$.

\section{Results}

\section{Content of transforming growth factor- $\beta 1$ in whey} protein concentrate and whey protein concentrate diet and control diet

WPC contains abundant TGF- $\beta 1$ as much as $0.06 \mathrm{ng} / \mathrm{mg}$. The content of TGF- $\beta 1$ in the WPC diet was $3 \mu \mathrm{g} / \mathrm{kg}$. We checked for the presence of TGF- $\beta 1$ in the control diet but we obtained negative results. The reason may be that the TGF- $\beta 1$ content in the control diet was too low to detect.

\section{Effects of dietary whey protein concentrate on growth performance}

Throughout the 19- $\mathrm{d}$ trial (pre-challenge), there were no differences in initial $(9.5$ (SD 0.6$) \mathrm{kg}$ ) and final BW (19.25 $(\mathrm{SD} 1.2) \mathrm{kg}$ ), daily gain $(513(\mathrm{SD} 32) \mathrm{g})(P=0.741)$, daily feed intake $(823(\mathrm{sD} 61) \mathrm{g})(P=0.362)$ and the gain:feed ratio $(0.62$ (sD 0.07)) $(P=0.641)$ between the WPC and control groups.

\section{Effects of dietary whey protein concentrate on the intestinal mucosal morphology and barrier function of piglets after lipopolysaccharide challenge}

Table 3 shows the jejunum morphology and barrier function of piglets. Compared with the control group, the pigs challenged with LPS had shorter $(P<0 \cdot 05)$ villus height and lower villus height:crypt depth ratio in the jejunum. LPS challenge also increased the FD4 flux and lowered $(P<0.05)$ TER. However, dietary WPC significantly prevented the LPS-induced decrease $(P<0.05)$ in villus height:crypt depth ratio and TER and limited the LPS-induced decrease in villous height and the LPS-induced increase in FD4 flux.

\section{Effects of dietary whey protein concentrate on the tight-junction proteins in the jejunal mucosa of piglets after lipopolysaccharide challenge}

Fig. 1 shows the protein expressions of occludin, claudin- 1 and ZO-1 in the jejunal mucosa of piglets. Compared with the control group, LPS challenge decreased $(P<0.05)$ protein

Table 3. Effects of dietary whey protein concentrate (WPC) on the jejunum morphology and barrier function of piglets* (Mean values with their standard errors; $n 6$ pigs)

\begin{tabular}{|c|c|c|c|c|c|}
\hline Items & Control & LPS & LPS + WPC & SEM & $P$ \\
\hline Villus height $(\mu \mathrm{m})$ & $385^{a}$ & $334.2^{c}$ & $359 \cdot 6^{b}$ & $6 \cdot 16$ & $<0.001$ \\
\hline Crypt depth $(\mu \mathrm{m})$ & $115 \cdot 33$ & $124 \cdot 17$ & $117 \cdot 92$ & $4 \cdot 32$ & 0.23 \\
\hline Villus height:crypt depth & $3 \cdot 36^{a}$ & $2 \cdot 71^{\mathrm{b}}$ & $3.06^{a}$ & 0.1 & 0.001 \\
\hline $\operatorname{TER}\left(\Omega \mathrm{cm}^{2}\right)$ & $67 \cdot 83^{a}$ & $49 \cdot 25^{b}$ & $59 \cdot 08^{a}$ & 3.04 & 0.002 \\
\hline FD4 flux $\left(\mu \mathrm{g} / \mathrm{cm}^{2}\right.$ per $\left.\mathrm{h}\right)$ & $1 \cdot 15^{c}$ & $2 \cdot 32^{a}$ & $1.49^{b}$ & 0.11 & $<0.001$ \\
\hline
\end{tabular}

LPS, lipopolysaccharide; FD4, mucosal:serosal flux of fluorescein isothiocyanate dextran $(4 \mathrm{kDa})$; TER, transepithelial electrical resistance.

a,b,c Mean values within a row with superscript letters were significantly different $(P<0.05)$.

* Control (non-challenged control), piglets receiving a control diet and injected with $0.9 \%$ sterile saline; LPS (LPS-challenged control), piglets receiving the same control diet and injected with Escherichia coli LPS; LPS + WPC (LPS challenged $+5 \%$ WPC), piglets receiving a $5 \%$ WPC diet and injected with LPS.

(A)

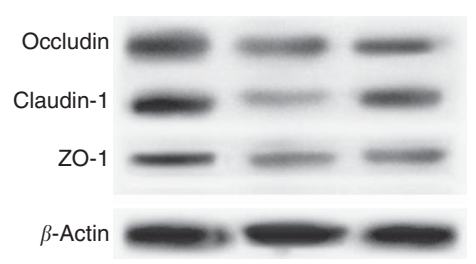

(B)

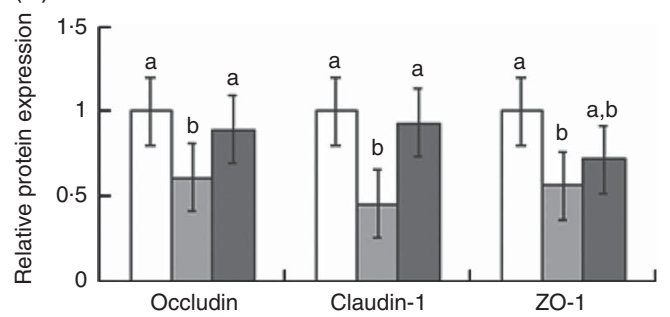

Fig. 1. Effects of dietary whey protein concentrate (WPC) on protein expressions of occludin, claudin-1 and zonula occludens-1 (ZO-1) in jejunal mucosa of piglets. (A) Representative blots of occludin, claudin, ZO-1 and $\beta$-actin in the jejunal mucosa of piglets. (B) Relative tight-junction protein expressions in the jejunal mucosa of piglets. Values are means $(n 6)$, and standard deviations represented by vertical bars. ${ }^{a, b}$ Mean values with unlike letters were significantly different $(P<0.05)$. The control sample was used as the reference sample. The protein expression of all samples was expressed as fold changes, calculated relative to the control group. $\square$, Control; $\square$, lipopolysaccharide (LPS); $\square$, LPS + WPC. Control (non-challenged control), piglets receiving a control diet and injected with $0.9 \%$ sterile saline; LPS (LPS-challenged control), piglets receiving the same control diet and injected with Escherichia coli LPS; LPS + WPC (LPS challenged $+5 \%$ WPC), piglets receiving a $5 \%$ WPC diet and injected with LPS. 
(A)

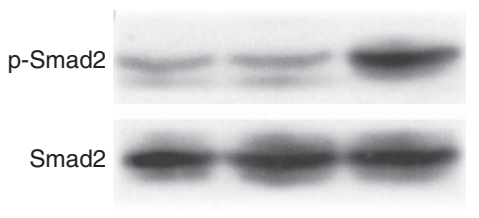

(B)

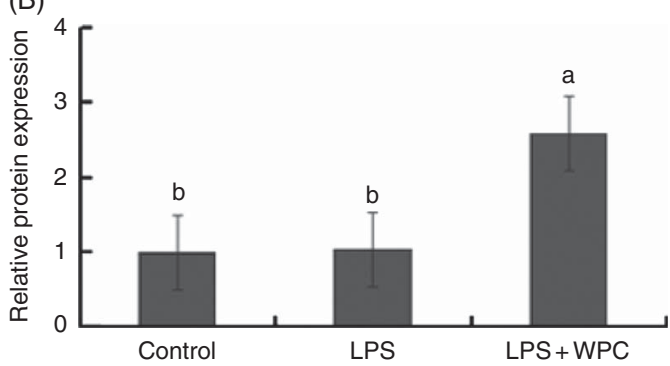

Fig. 3. Effects of dietary whey protein concentrate (WPC) on Smad2 activation in the jejunal mucosa of piglets. (A) Representative blots from one of the six pigs. (B) Values calculated as the ratio of the phosphorylation level ( $p$-Smad2):total level of Smad2. The control sample was used as the reference sample. The protein expression of all samples was expressed as fold changes, calculated relative to the control group. Values are means $(n 6)$, with standard deviations represented by vertical bars. ${ }^{\mathrm{a}, \mathrm{b}}$ Mean values with unlike letters were significantly different $(P<0.05)$. Control (non-challenged control), piglets receiving a control diet and injected with $0.9 \%$ sterile saline; LPS (lipopolysaccharide-challenged control), piglets receiving the same control diet and injected with Escherichia coli LPS; LPS + WPC (LPS challenged $+5 \%$ WPC), piglets receiving a $5 \%$ WPC diet and injected with LPS.

Table 5. Effects of dietary whey protein concentrate (WPC) on mRNA expressions of smad signals in the jejunal mucosa of piglets* (Mean values with their standard errors; $n 6$ pigs)

\begin{tabular}{lccccc}
\hline Items & Control & LPS & LPS +WPC & SEM & $P$ \\
\hline T $\beta R I$ & 1.00 & 1.12 & 1.25 & 0.17 & 0.573 \\
T $\beta$ RII & 1.00 & 1.24 & 1.31 & 0.20 & 0.651 \\
Smad2 & 1.00 & 1.24 & 1.33 & 0.21 & 0.573 \\
Smad3 & 1.00 & 1.32 & 1.27 & 0.15 & 0.302 \\
Smad4 & $1.00^{\mathrm{b}}$ & $1.41^{\mathrm{b}}$ & $2.54^{\mathrm{a}}$ & 0.39 & 0.033 \\
Smad7 & $1.00^{\mathrm{b}}$ & $1.24^{\mathrm{b}}$ & $3.43^{\mathrm{a}}$ & 0.53 & 0.009 \\
\hline
\end{tabular}

LPS, lipopolysaccharide; T $\beta R I$, transforming growth factor- $\beta$ receptor I; T $\beta R I I$, transforming growth factor- $\beta$ receptor II.

a,b Mean values within a row with unlike superscript letters were significantly different $(P<0.05)$.

* Control (non-challenged control), piglets receiving a control diet and injected with $0.9 \%$ sterile saline; lipopolysaccharide (LPS) (LPS-challenged control), piglets receiving the same control diet and injected with Escherichia coli LPS; LPS + WPC (LPS challenged $+5 \% \mathrm{WPC}$ ), piglets receiving a $5 \% \mathrm{WPC}$ diet and injected with LPS. The $2^{-\Delta \Delta C_{1}}$ method was used to analyse the relative expression (fold changes), calculated relative to the values in samples from the control pigs.

that have many beneficial effects on animal health ${ }^{(3,26,27)}$. Substantial evidence has shown that WPC exerts beneficial effects on a wide variety of gastrointestinal disorders such as inflammatory bowel disease and necrotising enterocolitis in animal models and clinical trials ${ }^{(1,2)}$. On the basis of this, we investigated the protective effect of supplementation with $5 \%$ WPC on intestinal morphology and barrier function after a 4 -h E. coli LPS challenge using a piglet model. LPS-induced intestinal injury in piglets is one of the well-established animal models for studying infant nutrition and gastrointestinal physiology $(17,28)$. In agreement with earlier reports ${ }^{(17,28)}$, the present study showed that LPS challenge decreased jejunal villus height and villus height:crypt depth ratio at $4 \mathrm{~h}$ after LPS challenge, which suggests that LPS caused acute intestinal mucosal damage. However, supplementation with 5\%WPC ameliorated LPS-induced intestinal injury by increased jejunal villus height and villus height:crypt depth ratio, which indicated that WPC improved intestinal morphology after damage. Similarly, Li et al. ${ }^{(29)}$ found that feeding WPC pigs had greater villus heights for preterm pigs. Enteral supplementation with colostrum has also been reported to increase villus growth in newborn pigs ${ }^{(7,30)}$. The gut is a target during endotoxin challenge. LPS could excessively activate inflammatory response and induce nitric oxide synthase production and lipid peroxidation, which finally led to local intestinal damage such as morphological damage and a breakdown in intestinal barrier function ${ }^{(17,19,21)}$. We conjectured that endotoxin-induced intestinal epithelial injury may be a result of oxygen-related free radical damage and inflammatory response. When exposed to LPS, the villi were frequently noted to have epithelial vacuolisation, lifting, sloughing and focal necrosis, which would lead to villi shortening as a result. Our study also demonstrated that LPS can damage the intestinal morphology and barrier integrity. WPC contains abundant bioactive substances such as anti-inflammatory cytokines and antioxidative factors (e.g. TGF- $\beta$, EGF, LF) that can counteract the effects of LPS, thus protecting the intestinal morphology and barrier integrity ${ }^{(4,31-35)}$. In the present experiment, consistent with improved intestinal morphology, WPC improved intestinal barrier function, indicated by increased TER and decreased FD4 flux in the jejunum of piglets compared with the LPS group. Our data were supported by the results of Hering et al. ${ }^{(4)}$, who reported that WPC protects against interferon- $\gamma$-induced barrier impairment by increased TER and decreased fluorescein permeability in HT-29/B6 cells. Moreover, WPC also reduced intestinal permeability in preterm pigs ${ }^{(29)}$. To our knowledge, the present study is the first to determine the effects of dietary supplementation with WPC on the attenuation of LPS-induced intestinal injury in weaned piglets.

The tight-junction (TJ) is a major cellular component for maintenance of tissue integrity and barrier function. It has a complex molecular composition that forms the continuous intercellular barrier against external agents in the intestine. The integral membrane components of $\mathrm{TJ}$ include claudins, occludins and $\mathrm{ZO}^{(24,36)}$. In our present study, consistent with the improved intestinal morphology and barrier function, WPC prevented the LPS-induced decrease in claudin-1, occludin and ZO-1 expressions. Our observations were supported by Hering et $a l^{(4)}$ and Visser et $a l^{(37)}$, who reported that milk protein components improved intestinal barrier function, in part, by altering the expressions and functions of claudins. In our present study, WPC may have partially improved the intestinal barrier function via improving the expressions of intestinal $\mathrm{TJ}$ proteins. 
(A)

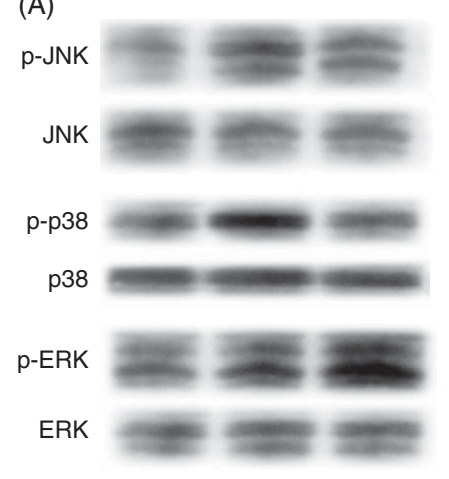

(B)

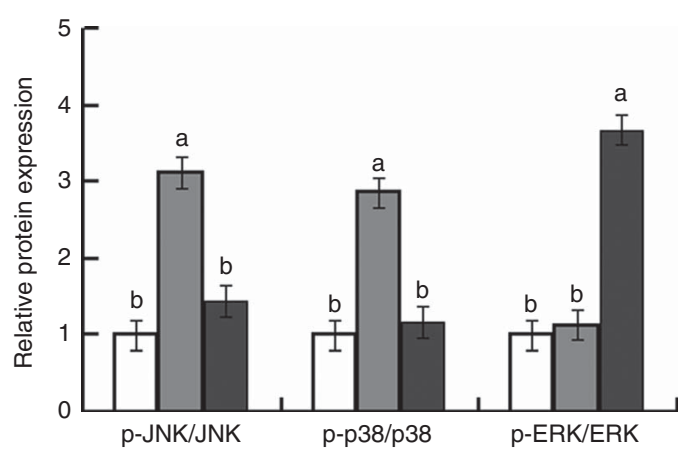

Fig. 4. Effects of whey protein concentrate (WPC) on mitogen-activated protein kinases (MAPK) signal pathways in the jejunal mucosa of piglets. The three MAPK are the c-Jun NH2-terminal kinase (JNK), p38 MAPK and extracellular regulated kinases (ERK 1/2). (A) Representative blots from one of the six pigs. (B) Values calculated as the ratios of their phosphorylation levels (phospho-JNK:phospho-p38:phospho-ERK (p-JNK:p-p38:p-ERK)) to the total levels of MAPK. The values in samples from the control were used as the reference sample. The protein expression of all samples was expressed as fold changes, calculated relative to the values from the control group. Values are means ( $n$ 6), with standard deviations represented by vertical bars. ${ }^{\mathrm{a}, \mathrm{b}}$ Mean values with unlike letters were significantly different $(P<0.05)$. $\square$, Control; $\square$, lipopolysaccharide (LPS); $\square$, LPS + WPC. Control (non-challenged control), piglets receiving a control diet and injected with $0.9 \%$ sterile saline; LPS (LPS-challenged control), piglets receiving the same control diet and injected with Escherichia coli LPS; LPS + WPC (LPS challenged $+5 \%$ WPC), piglets receiving a $5 \%$ WPC diet and injected with LPS. JNK, c-jun N-terminal kinase; p-JNK, phospho-JNK; ERK, extracellular regulated kinases; p-ERK, phospho-ERK.

Cytokines also participate in the regulation of the intestinal barrier integrity ${ }^{(38)}$. Over-production of pro-inflammatory cytokines has a negative influence on gut integrity and epithelial function $^{(39)}$. The TJ barrier disruptive actions of TNF- $\alpha$ have been well established ${ }^{(40)}$. It has been reported that interferon- $\gamma$-induced reductions in epithelial barrier function are linked to decreases in the expressions of $\mathrm{TJ}$ proteins such as occludin and $\mathrm{ZO}-\mathrm{1}^{(41)}$. In the present study, the expressions of pro-inflammatory cytokines such as TNF- $\alpha$, IL- $1 \beta$, IL- 6 and IL- 8 were elevated in the jejunal mucosa of piglets subjected to LPS challenge. Consistent with the improved intestinal integrity by WPC supplementation, WPC decreased the TNF- $\alpha$, IL- $1 \beta$, IL- 6 and IL-8 gene expressions compared with the LPS-challenged group. In line with our findings, Sprong et $a l^{(1)}$ reported that cheese whey protein protected rats against mild dextran sulphate Na-induced colitis by inhibiting the expressions of inflammatory cytokines. Whey product has demonstrated a number of anti-inflammatory effects including decreased cytokine release in rodent models after exposure to LPS ${ }^{(42)}$. It is possible that the protective effects of WPC supplementation on intestinal integrity were closely related to reducing the expressions of intestinal pro-inflammatory cytokines. According to the above results, we speculate that WPC may exert beneficial effects in intestinal damage by enhancing intestinal integrity and barrier function.

WPC contains abundant TGF- $\beta 1^{(5)}$, but whether TGF- $\beta 1$ plays a role in these protection processes is not clear. TGF- $\beta 1$ is of particular interest as it has known effects in a remarkable number of biological processes including epithelial cell growth and differentiation ${ }^{(11)}$, restitution of intestinal epithelium after injury $^{(12,43)}$ and immune regulation ${ }^{(5)}$. TGF- $\beta$ has been reported to play an important role in the post-weaning adaptation process in the intestine of pigs ${ }^{(9,12)}$. In our present experiment, dietary supplementation with $5 \% \mathrm{WPC}$ increased the TGF- $\beta 1$ protein expression in the jejunum mucosa of piglets compared with the LPS-challenged pigs. Similarly, Andújar et al. ${ }^{(44)}$ found that TGF- $\beta 1$ positively regulates gastrointestinal ulcer healing.
TGF- $\beta$ was also reported to provide protection against dextran sodium sulphate-induced colitis and LPS-induced endotoxaemia/shock in rodents ${ }^{(45,46)}$, and it is likely that the increased TGF- $\beta 1$ concentration by supplementation with WPC is directly responsible for the protection. Therefore, our hypothesis is that the beneficial role exerted by WPC in intestinal barrier protection may be partially influenced by TGF$\beta 1$ in the intestinal mucosa. We speculated that the increased expression of TGF- $\beta 1$ may due to the TGF- $\beta 1$ in WPC, as TGF$\beta 1$ in the diet can be absorbed by the intestine in vivo and TGF$\beta$ retains biological activity when given as a supplement in infant formula ${ }^{(31,47,48)}$. It is possible that the higher presence of TGF- $\beta 1$ is from dietary WPC by intestinal absorption.

To determine whether the TGF- $\beta 1$ signalling pathway is involved in WPC exerting beneficial effects on LPS-induced intestinal injury, we next evaluated the canonical downstream substrate of TGF- $\beta$ signal. The canonical TGF- $\beta$ signalling pathway is mediated by Smad family proteins ${ }^{(13)}$. When TGF- $\beta$ ligands reach the membrane of target cells, they bind directly to $\mathrm{T} \beta$ RII, which leads to the recruitment of $\mathrm{T} \beta \mathrm{RI}$, and T $\beta$ RII then trans-phosphorylates $\mathrm{T} \beta \mathrm{RI}$, enabling the $\mathrm{T} \beta \mathrm{RI}$ kinase domain to act on cytoplasmic Smad proteins, and thereby propel downstream signalling actions. Smad 2 and 3 are receptorregulated Smad. Following stimulation by TGF- $\beta, \operatorname{Smad} 2$ and Smad3 become phosphorylated. Phosphorylated Smad2 and Smad3 can complex with Smad4 (the common mediator Smad) and then translocate to the nucleus and regulate gene expression $^{(13)}$. In the present study, we observed that supplementation with WPC promoted phosphorylated-Smad2 expression and mRNA expressions of Smad4 and Smad7 in the jejunal mucosa compared with the LPS-challenged pigs fed the control diet, which indicates that canonical Smad signalling pathways were activated. In line with our study, a recent study has revealed that oral administration of TGF- $\beta 1$ protects the immature gut from injury via Smad protein-dependent signalling pathways ${ }^{(49)}$. Ozawa et al. ${ }^{(31)}$ have also found that TGF- $\beta$ in cows' milk provided protection against experimental 
colitis and endotoxaemia by inducing Smad2 phosphorylation and the transcription of the TGF- $\beta /$ Smad target genes TGF- $\beta$ itself and Smad7 in vitro. It is also reported that TGF- $\beta 1$ enhancement of epithelial barrier function was mediated partly by Smad2/3 signalling pathways ${ }^{(50)}$. Consequently, in the present study, we speculated that the WPC may have protected the intestinal epithelial barrier from LPS-induced intestinal injury partially through TGF- $\beta 1$ canonical Smad pathways directly or indirectly.

Apart from canonical Smad pathways, MAPK has been reported to be involved in TGF- $\beta$ actions ${ }^{(14)}$. The three primary MAPK signalling pathways are the ERK $1 / 2$, p38 and JNK. It has been demonstrated that MAPK become activated when stimulated by LPS $^{(51)}$. Moreover, a recent study showed that weaning stress activates p38, JNK and ERK 1/2 signalling pathways in the intestine, which may be an important mechanism of weaningassociated enteric disorders of piglets ${ }^{(24)}$. Thus far, there are a few reports investigating the effects of WPC on MAPK signalling pathways ${ }^{(52)}$. In the present study, we observed an increase in the phospho-p38 and p-JNK in the jejunum of LPS-challenged pigs and we demonstrated, for the first time, that dietary WPC decreased the relative protein levels of phosphorylated p38 and JNK, while increasing p-ERK $1 / 2$ protein levels, indicating that WPC inhibited the JNK and p38 signalling pathways while activating ERK 1/2 signalling in LPS-challenged pigs. In general, ERK delivers a survival signal, whereas JNK and p38 are associated with the induction of cell apoptosis under stressful conditions ${ }^{(53,54)}$. Cell apoptosis can disrupt intestinal mucosal integrity ${ }^{(55)}$. Activation of ERK pathways and inhibition of $\mathrm{p} 38$ and JNK pathways also improved intestinal barrier function in weaned pigs ${ }^{(56)}$. The ERK $1 / 2$ cascade can be activated by growth factors and preferentially regulates cell growth and differentiation. There is evidence that activation of the ERK $1 / 2$ signalling is linked to the TGF- $\beta 1$-induced modulation of TJ permeability and wound closure ${ }^{(56,57)}$. TGF- $\beta$ has been shown to attenuate IL- $1 \beta$-induced pro-inflammatory cytokine production in immature human intestinal epithelia cells by inhibiting ERK signalling ${ }^{(58)}$. In our study, it is possible that the protective effects of WPC on intestinal integrity after exposure to LPS are also related to activation of ERK $1 / 2$ and inhibition of JNK and p38 MAPK signalling pathways

Other bioactive substances than TGF- $\beta 1$ in WPC may be implied in the effects of WPC. EGF is another important growth factor in WPC that has protective barrier effects on intestinal epithelia and has often been related to effects on cell proliferation and/or epithelial restitution, which could indirectly or secondarily affect the $\mathrm{TJ}^{(59)}$. Accumulating evidence has shown that EGF/EGF receptor signal improves healing of the gastrointestinal tract and enhances gut integrity and intestinal barrier function ${ }^{(32,60,61)}$. In addition, LF is a multifunctional glycoprotein present at high concentrations in milk that exerts antibacterial, immunemodulating and anti-inflammatory effects on intestinal health ${ }^{(33)}$. Studies have found that LF could directly induce enterocyte growth and proliferation and improve gut barrier function ${ }^{(34,62)}$. However, it is still unclear whether these constituents of WPC are the crucial biological factors that provide beneficial effects.

In summary, the present study demonstrated that dietary supplementation with WPC attenuates LPS-induced intestinal injury via improving mucosal barrier function, alleviating intestinal inflammation and influencing TGF- $\beta 1$, Smad and MAPK signalling pathways.

\section{Acknowledgements}

This research was jointly supported by the National Natural Science Foundation of China (31472103), the Special Fund for Agroscientific Research in Public Interest (201403047).

The authors' contributions are as follows: C. H. and X. H. contributed to the study design; K. X. collected and analysed the data and wrote the paper; L. J., S. C and Z. S. participated in data collection; C. H. and X. H. had the primary responsibility for the final content. All the authors read and approved the final version of the manuscript.

The authors declare that they have no conflicts of interest.

\section{References}

1. Sprong RC, Schonewille AJ \& van der Meer R (2010) Dietary cheese whey protein protects rats against mild dextran sulfate sodium-induced colitis: role of mucin and microbiota. J Dairy Sci $93,1364-1371$.

2. Playford RJ, Macdonald CE \& Johnson WS (2000) Colostrum and milk-derived peptide growth factors for the treatment of gastrointestinal disorders. Am J Clin Nutr 72, 5-14.

3. Marshall K (2004) Therapeutic applications of whey protein. Altern Med Rev 9, 136-156.

4. Hering NA, Andres S, Fromm A, et al. (2011) Transforming growth factor- $\beta$, a whey protein component, strengthens the intestinal barrier by upregulating claudin-4 in HT-29/B6 cells. J Nutr 141, 783-789.

5. Penttila IA (2010) Milk-derived transforming growth factor-beta and the infant immune response. $J$ Pediatr 156, S21-S25.

6. Cross ML \& Gill HS (1999) Modulation of immune function by a modified bovine whey protein concentrate. Immunol Cell Biol 77, 345-350.

7. Penttila IA, van Sprie AB, Zhang MF, et al. (1998) Transforming growth factor-beta levels in maternal milk and expression in postnatal rat duodenum and ileum. Pediatr Res 44, 524-531.

8. Barnard JA, Warick GJ \& Gold LI (1993) Localisation of transforming growth factor $\beta$ in the normal murine small intestine and colon. Gastroenterology 105, 67-73.

9. Mei J \& Xu RJ (2005) Transient changes of transforming growth factor- $\beta$ expression in the small intestine of the pig in association with weaning. Br J Nutr 93, 37-45.

10. Godlewski MM, Hallay N, Bierła JB, et al. (2007) Molecular mechanism of programmed cell death in the gut epithelium of neonatal piglets. J Physiol Pharmacol 3, Suppl., $97-113$.

11. van't Land B, Meijer HP, Frerichs J, et al. (2002) Transforming growth factor-beta2 protects the small intestine during methotrexate treatment in rats possibly by reducing stem cell cycling. Br J Cancer 87, 113-118.

12. Xiao K, Song ZH, Jiao LF, et al. (2014) Developmental changes of TGF- $\beta 1$ and smads signaling pathway in intestinal adaption of weaned pigs. PLOS ONE 9, e104589.

13. Weiss A \& Attisano L (2013) The TGF beta superfamily signaling pathway. Wiley Interdiscip Rev Dev Biol 2, 47-63.

14. Derynck R \& Zhang YE (2003) Smad-dependent and Smadindependent pathways in TGF- $\beta$ family signalling. Nature 425, 577-584. 
15. Association of Official Analytical Chemists (2002) Official Methods of Analysis, Association of Official Analytical Chemists, 17th ed. Washington, DC: AOAC.

16. Liu YL, Huang JJ, Hou YQ, et al. (2008) Dietary arginine supplementation alleviates intestinal mucosal disruption induced by Escherichia coli lipopolysaccharide in weaned pigs. Br J Nutr 100, 552-560.

17. Liu YL, Chen F, Odle J, et al. (2012) Fish oil enhances intestinal integrity and inhibits TLR4 and NOD2 signaling pathways in weaned pigs after LPS challenge. J Nutr 142, 2017-2024.

18. Pi DA, Liu YL, Shi HF, et al. (2014) Dietary supplementation of aspartate enhances intestinal integrity and energy status in weanling piglets after lipopolysaccharide challenge. $J$ Nutr Biochem 25, 456-462.

19. Mercer DW, Smith GS, Cross JM, et al. (1996) Effects of lipopolysaccharide on intestinal injury: potential role of nitric oxide and lipid peroxidation. J Surg Res 63, 185-192.

20. Alscher KT, Phang PT, McDonald TE, et al. (2001) Enteral feeding decreases gut apoptosis, permeability, and lung inflammation during murine endotoxemia. Am $J$ Physiol Gastrointest Liver Physiol 281, G569-G576.

21. Touchette KJ, Carroll JA, Allee GL, et al. (2002) Effect of spraydried plasma and lipopolysaccharide exposure on weaned pigs: I. Effects on the immune axis of weaned pigs. J Anim Sci 80, 494-501.

22. Ewaschuk J, Endersby R, Thiel D, et al. (2007) Probiotic bacteria prevent hepatic damage and maintain colonic barrier function in a mouse model of sepsis. Hepatology 46, 841-850.

23. Wallace JL, Steel G, Whittle B, et al. (1987) Evidence for platelet-activating factor as a mediator of endotoxin-induced gastrointestinal damage in the rat: effects of three plateletactivating factor antagonists. Gastroenterology 93, 765-773.

24. Hu CH, Xiao K, Luan ZS, et al. (2013) Early weaning increases intestinal permeability, alters expression of cytokine and tight junction proteins, and activates mitogen- activated protein kinases in pigs. J Anim Sci 91, 1094-1101.

25. Moeser AJ, Ryan KA, Nighot PK, et al. (2007) Gastrointestinal dysfunction induced by early weaning is attenuated by delayed weaning and mast cell blockade in pigs. Am J Physiol Gastrointest Liver Physiol 293, G413-G421.

26. Verhasselt V, Milcent V, Cazareth J, et al. (2008) Breast milk-mediated transfer of an antigen induces tolerance and protection from allergic asthma. Nat Med 14, 170-175.

27. Hsieh CC, Hernández-Ledesma B, Fernández-Tomé S, et al. (2015) Milk proteins, peptides, and oligosaccharides: effects against the 21st century disorders. Biomed Res Int 2015 , 146840.

28. Hou YQ, Wang L, Zhang W, et al. (2012) Protective effects of $\mathrm{N}$-acetylcysteine on intestinal functions of piglets challenged with lipopolysaccharide. Amino Acids 43, 1233-1242.

29. Li YQ, Mette VQ, Jiang PP, et al. (2013) Whey protein processing influences formula-induced gut maturation in preterm pigs. J Nutr 143, 1934-1942.

30. Mei J, Zhang YQ, Wang T, et al. (2006) Oral ingestion of colostrum altersintestinal transforming growth factor-beta receptor intensity in newborn pigs. Livest Sci 105, 214-222.

31. Ozawa T, Miyata M, Nishimura M, et al. (2009) Transforming growth factor- $\beta$ activity in commercially available pasteurized cow milk provides protection against inflammation in mice. J Nutr 139, 69-75.

32. Clark JA, Doelle SM, Halpern MD, et al. (2006) Intestinal barrier failure during experimental necrotizing enterocolitis: protective effect of EGF treatment. Am J Physiol Gastrointest Liver Physiol 291, G938-G949.

33. Kuhara T, Tanaka A, Yamauchi K, et al. (2014) Bovine lactoferrin ingestion protects against inflammation via IL-11 induction in the small intestine of mice with hepatitis. $\mathrm{Br} J$ Nutr 111, 1801-1810.

34. Buccigrossi V, de Marco G, Bruzzese E, et al. (2007) Lactoferrin induces concentration-dependent functional modulation of intestinal proliferation and differentiation. Pediatr Res 61, 410-414.

35. Xu R, Liu N, Xu X, et al. (2011) Antioxidative effects of whey protein on peroxide -induced cytotoxicity. J Dairy Sci $\mathbf{9 4 ,}$ 3739-3746.

36. Suzuki T (2013) Regulation of intestinal epithelial permeability by tight junctions. Cell Mol Life Sci 70, 631-659.

37. Visser JT, Lammers K, Hoogendijk A, et al. (2010) Restoration of impaired intestinal barrier function by the hydrolysed casein diet contributes to the prevention of type 1 diabetes in the diabetes-prone BioBreeding rat. Diabetologia $\mathbf{5 3}$, 2621-2628.

38. Al-Sadi R, Boivin M \& Ma T (2009) Mechanism of cytokine modulation of epithelial tight junction barrier. Front Biosci (Landmark Ed) 14, 2765-2778.

39. Pié S, Lallès JP, Blazy F, et al. (2004) Weaning is associated with an upregulation of expression of inflammatory cytokines in the intestine of piglets. J Nutr 134, 641-647.

40. Ma TY, Boivin MA, Ye D, et al. (2005) Mechanism of TNF- $\alpha$ modulation of Caco-2 intestinal epithelial tight junction barrier: role of myosin light-chain kinase protein expression. Am J Physiol Gastrointest Liver Physiol 288, G422-G430.

41. Blikslager AT, Moeser AJ, Gookin JL, et al. (2007) Restoration of barrier function in injured intestinal mucosa. Physiol Rev 87, 545-564

42. Beaulieu J, Girard D, Dupont C, et al. (2009) Inhibition of neutrophil infiltration by a malleable protein matrix of lactic acid bacteria-fermented whey proteins in vivo. Inflamm Res 58, $133-138$

43. McKaig BC, Hughes K, Tighe PJ, et al. (2002) Differential expression of TGF- $\beta$ isoforms by normal and inflammatory bowel disease intestinal myofibroblasts. Am J Physiol Cell Physiol 282, C172-C182.

44. Andújar I, Ríos JL, Giner RM, et al. (2013) Shikonin promotes intestinal wound healing in vitro via induction of TGF- $\beta$ release in IEC-18 cells. Eur J Pharm Sci 49, 637-641.

45. Hahm KB, Im YH, Parks TW, et al. (2001) Loss of transforming growth factor $\beta$ signalling in the intestine contributes to tissue injury in inflammatory bowel disease. Gut 49, 190-198.

46. McCartney-Francis N, Jin W \& Wahl SM (2004) Aberrant toll receptor expression and endotoxin hypersensitivity in mice lacking a functional TGF- $\beta 1$ signaling pathway. J Immunol 172, 3814-3821.

47. Ando T, Hatsushika K, Wako M, et al. (2007) Orally administered TGF-beta is biologically active in the intestinal mucosa and enhances oral tolerance. J Allergy Clin Immunol 120, 916-923.

48. Penttila IA, Flesch IE, McCue AL, et al. (2003) Maternal milk regulation of cell infiltration and interleukin 18 in the intestine of suckling rat pups. Gut 52, 1579-1586.

49. Shiou SR, Yu YY, Guo Y, et al. (2013) Oral administration of transforming growth factor- $\beta 1$ (TGF- $\beta 1$ ) protects the immature gut from injury via smad protein-dependent suppression of epithelial nuclear factor $\kappa \mathrm{B}(\mathrm{NF}-\mathrm{\kappa B})$ signaling and proinflammatory cytokine production. J Biol Chem 288, 34757-34766.

50. Howe KL, Reardon C, Wang A, et al. (2005) Transforming growth factor- $\beta$ regulation of epithelial tight junction proteins enhances barrier function and blocks enterohemorrhagic Escherichia coli O157:H7-induced increased permeability. Am J Pathol 167, 1587-1597.

51. Chen X, Yang X, Liu T, et al. (2012) Kaempferol regulates MAPKs and NF-kappaB signaling pathways to attenuate 
LPS-induced acute lung injury in mice. Int Immunopharmacol 14, 209-216.

52. Rusu D, Drouin R, Pouliot Y, et al. (2010) A bovine whey protein extract stimulates human neutrophils to generate bioactive IL-1Ra through a NF-kappa B- and MAPK-dependent mechanism. J Nutr 140, 382-391.

53. Benhar M, Dalyot I, Engelberg D, et al. (2001) Enhanced ROS production in oncogenically transformed cells potentiates c-Jun N-terminal kinase and p38 mitogen-activated protein kinase activation and sensitization to genotoxic stress. Mol Cell Biol 21, 6913-6926.

54. Ku BM, Lee YK, Jeong JY, et al. (2007) Ethanol-induced oxidative stress is mediated by p38 MAPK pathway in mouse hippocampal cells. Neurosci Lett 419, 64-67.

55. Zhu LH, Xu JX, Zhu SW, et al. (2014) Gene expression profiling analysis reveals weaning-induced cell cycle arrest and apoptosis in the small intestine of pigs. J Anim Sci $\mathbf{9 2}$, 996-1006.

56. Song ZH, Xiao K, Ke YL, et al. (2014) Zinc oxide enhances intestinal barrier partially through the mitogen-activated protein kinases and transforming growth factor- $\beta 1$ signaling pathways in weaned pigs. Innate Immun $\mathbf{0}, 1-8$.
57. Ma ZJ, Misawa H \& Yamaguchi M (2001) Stimulatory effect of zinc on insulin-like growth factor-I and transforming growth factor-beta1 production with bone growth of newborn rats. Int J Mol Med 8, 623-628.

58. Rautava S, Nanthakumar NN, Dubert-Ferrandon A, et al. (2011) Breast milk-transforming growth factor- $\beta 2$ specifically attenuates IL-1 $\beta$-induced inflammatory responses in the immature human intestine via an SMAD6-and ERK-dependent mechanism. Neonatology 99, 192-201.

59. Khailova L, Dvorak K, Arganbright KM, et al. (2009) Changes in hepatic cell junctions structure during experimental necrotizing enterocolitis: effect of EGF treatment. Pediatr Res 66, 140-144.

60. Haedo W, Gonzalez T, Mas JA, et al. (1996) Oral human recombinant epidermal growth factor in the treatment of patients with duodenal ulcer. Rev Esp Enferm Dig 88, 409-418.

61. Tarnawski A, Stachura J, Durbin T, et al. (1992) Increased expression of epidermal growth factor receptor during the gastric ulcer healing in rats. Gastroenterology 102, 695-698.

62. Wu J, Chen J, Wu W, et al. (2014) Enteral supplementation of bovine lactoferrin improves gut barrier function in rats after massive bowel resection. Br J Nutr 112, 486-492. 